\title{
Eczema herpeticum emerging during atopic dermatitis in infancy
}

\author{
Aysegül Ertuğrul ${ }^{\oplus}$, Zeynep Şengül Emeksiz ${ }^{\oplus}$, Ezgi Ulusoy Severcan ${ }^{\oplus}$ \\ Serap Özmen ${ }^{\oplus}$ İlknur Bostancı ${ }^{\odot}$ \\ Department of Pediatric Allergy and Clinical Immunology, Health Sciences University Dr. Sami Ulus Maternity and Children \\ Training and Research Hospital, Ankara, Turkey.
}

\begin{abstract}
Background. Eczema herpeticum $(\mathrm{EH})$ is an acute disseminated viral infection that develops in the presence of an existing skin lesion, often on the ground of atopic dermatitis (AD). Morbidity and mortality of EH can be minimized by starting antiviral therapy at the earliest time in diagnosis.

Case. Herein we report five infants diagnosed with EH in the course of AD treatment. All patients had early onset, moderate to severe AD and needed intermittent topical corticosteroid (TCS) therapy. In physical examination, newly formed, TCS-resistant vesiculo-papular skin lesions were recognised on the present dermatitis. The presence of AD with food allergy and moderate to severe eosinophilia were other prominent findings.
\end{abstract}

Conclusion. All patients were misdiagnosed as AD exacerbation. Therefore, EH should be considered in the differential diagnosis of AD exacerbation especially in the infants with moderate to severe AD.

Key words: atopic dermatitis, eczema herpeticum, Kaposi's varicelliform eruption, Herpes Simplex virus.

Atopic dermatitis (AD) is the most common inflammatory skin disease in childhood. The worldwide prevalence of AD has been reported to be $8-20 \%$. It is characterized by chronic relapsing itchy lesions with different distribution according to age. ${ }^{1,2}$ Eczema herpeticum (EH) (Kaposi's varicelliform eruption) is an acute disseminated viral infection, usually Herpes Simplex virus (HSV) type 1, that develops in the presence of an existing skin lesion, often on the ground of AD. Eczema herpeticum was first described in children and occurs with a higher prevalence in childhood however it can occur at any age. ${ }^{3}$ Pathogenesis of EH is not fully understood but deterioration of skin barrier integrity and imbalance of the immune

$\triangle$ Aysegül Ertuğrul

aysegull.ertugrul@gmail.com

Received 11th March 2019, revised 22nd October 2019, accepted 15th November 2019.

The results are also presented as a poster in European Academy of Allergy and Clinical Immunology Congress, Thematic Poster Session, 29 May 2018, Munich, Germany. system are accused. Diagnosis is based on clinical findings. Early initiation of anti-viral therapy can prevent significant morbidity and mortality. ${ }^{4}$

Herein we report five infants diagnosed with $\mathrm{EH}$ in the course of $\mathrm{AD}$ treatment. A wide spectrum of clinical manifestations has been observed in the patients. We highlighted the clinical features, associations and therapeutic options in the context of the literature.

\section{Case Report}

The medical files of 1355 pediatric patients with AD between January 1, 2017 to December 31, 2017 at the pediatric allergy clinic in a tertiary centre (Allergy and Immunology Department of Health Sciences University Dr. Sami Ulus Maternity and Children's Health Training and Research Hospital Turkey) were reviewed retrospectively. Five of 1355 patients (\% 0.36) were found to have EH during follow-up. The patients were treated by a multidisciplinary 
approach including departments of pediatric allergy immunology, infectious disease and dermatology. The characteristics of the cases are summarized in Table I.

All of the patients had early onset and moderate to severe $\mathrm{AD}$ and needed intermittent topical corticosteroid (TCS) therapy. TCS had been applied on the acute eczematous lesions within the past month in all patients. Despite repetitive TCS requirement, due to age limitation, topical calcineurin inhibitors had not been used. The most frequently affected area of the skin was the head region especially cheeks, followed by extremities and trunk (Fig. 1). The diagnosis of $\mathrm{EH}$ was made clinically by detection of active vesiculo-papules on the existing persistent eczematous lesions of the skin. The vesiculopustular lesions of $\mathrm{EH}$ recovered within in 5-15 days after onset of accurate treatment.

The laboratory findings are summarized in Table II. There was no significant increase in C-reactive protein (range $=0-3 \mathrm{mg} / \mathrm{L}$ ) or erythrocyte sedimentation rate (rate $=0-20$ $\mathrm{mm} / \mathrm{hr}$ ) although the white blood cells of the patients were high at diagnosis (mean 18.540 $\pm 6247 / \mu \mathrm{l})$. Serum Herpes Simplex Virus (HSV)1 and HSV-2 IgM/IgG serology was negative in all patients. Due to refractory fever and irritability, lumbar puncture was performed in case 4 which revealed positive HSV type1 by using Polymerase chain reaction (PCR) in the cerebrospinal fluid. The immunologic profiles of the patients were within normal limits despite one patient exhibited transient hypogammaglobulinemia of infancy. Atopy was evaluated by skin prick tests and specific IgE measurements. Standardized allergen extracts (Stallergens, Antony, France) were used for skin prick tests. Specific IgE serum levels to food allergens were performed on enzyme immunoassay system (Immulite Siemens, Germany). Food allergy was confirmed by the food challenge test in 4 patients in the follow-

Table I. The characteristics of the patients.

\begin{tabular}{|c|c|c|c|c|c|c|c|}
\hline 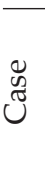 & ڤ્ & $\begin{array}{c}\text { Age } \\
\text { (month) }\end{array}$ & $\begin{array}{c}\text { Age (month) } \\
\text { onset of AD/ } \\
\text { diagnosis of EH }\end{array}$ & $\begin{array}{l}\text { Distribution and characteristics of skin } \\
\text { lesions }\end{array}$ & Fever & $\begin{array}{l}\text { Seborrheic } \\
\text { dermatitis }\end{array}$ & $\begin{array}{l}\text { AD severity } \\
\text { SCORAD } \\
\text { index during } \\
\text { EH/ currently }\end{array}$ \\
\hline 1 & $\mathrm{M}$ & 19 & $2 / 9$ & $\begin{array}{c}\text { Grouped vesiculo-pustules on the } \\
\text { eczematous skin of cheeks, left eyebrow } \\
\text { and extremities, with secondary } \\
\text { impetiginization }\end{array}$ & - & $\begin{array}{l}\text { Over the } \\
\text { scalp }\end{array}$ & $60-57.2$ \\
\hline 2 & $\mathrm{~F}$ & 22 & $1 / 9$ & $\begin{array}{l}\text { Crusted grouped vesiculo-pustules on the } \\
\text { eczematous skin of the cheeks, chin and } \\
\text { forehead, eczematous plaques on the neck } \\
\text { and trunk }\end{array}$ & - & - & $40-30$ \\
\hline 3 & $\mathrm{~F}$ & 25 & $1.5 / 4$ & $\begin{array}{l}\text { Grouped vesiculo-pustules on the } \\
\text { eczematous skin of cheeks with ulceration } \\
\text { and secondary impetiginization, grouped } \\
\text { vesicles on the eczematous skin of hand and } \\
\text { eczematous plaques on the trunk }\end{array}$ & - & $\begin{array}{l}\text { Over the } \\
\text { scalp }\end{array}$ & $66.7-0$ \\
\hline 4 & M & 24 & $2 / 4$ & $\begin{array}{l}\text { Grouped vesiculo-pustules and blisters on } \\
\text { the eczematous skin of the cheeks, chin, } \\
\text { ears, neck, extensor aspects of the knees and } \\
\text { elbows with secondary impetiginization }\end{array}$ & + & $\begin{array}{l}\text { Behind the } \\
\text { ear }\end{array}$ & $85.7-40.7$ \\
\hline 5 & $\mathrm{~F}$ & 17 & $4 / 4$ & $\begin{array}{l}\text { Grouped vesicles on the cheeks, eyelid and } \\
\text { eyebrow with secondary impetiginization }\end{array}$ & - & - & $47.4-20$ \\
\hline
\end{tabular}

M: male, F: female, AD: atopic dermatitis, ED: eczema herpeticum. 

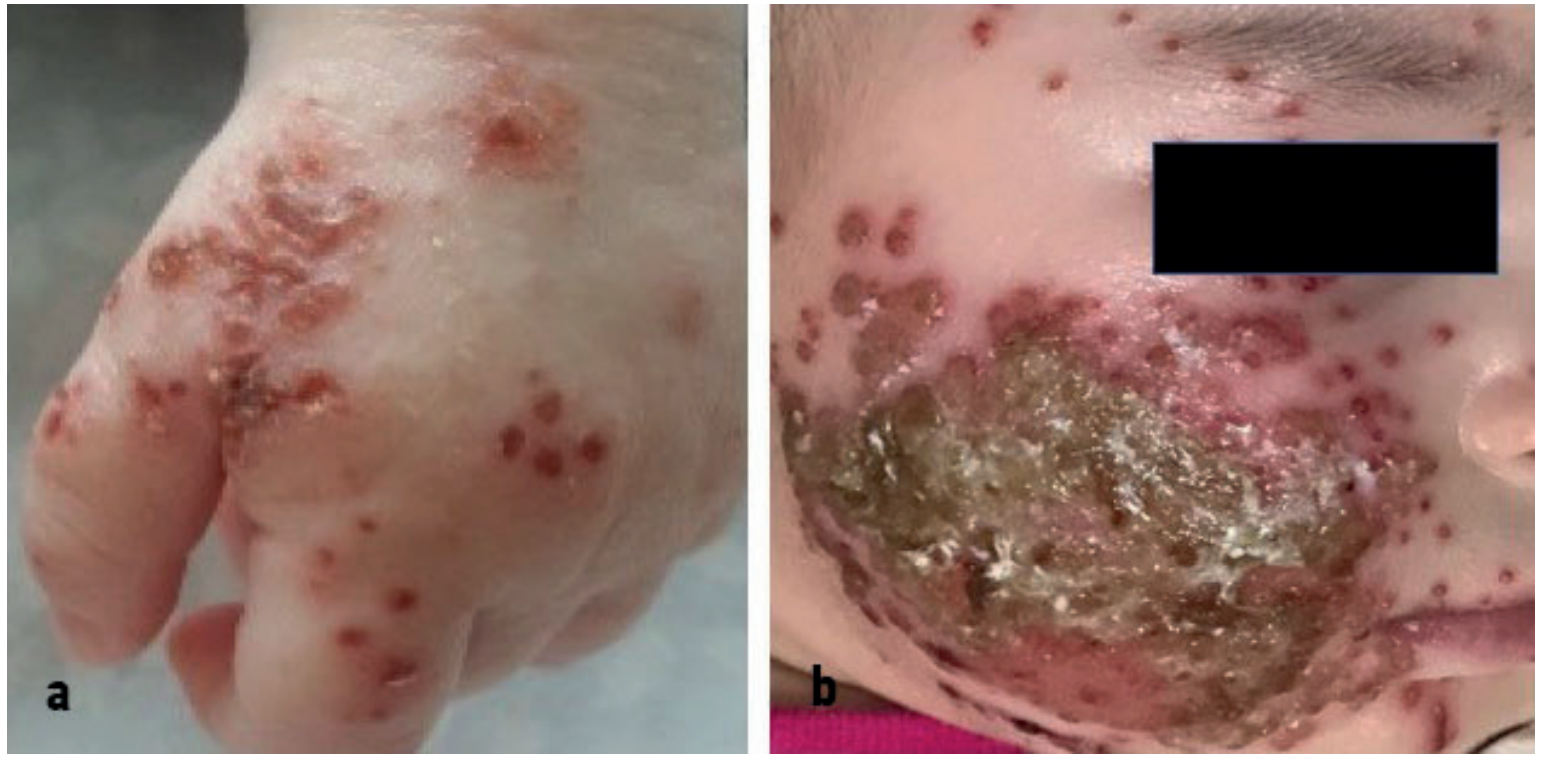

Fig. 1a. Grouped vesiculo-papules on the eczematous skin of hand. 1b. Grouped vesiculo-papules on the eczematous skin of cheeks, eyelid and eyebrow with ulceration and secondary impetiginisation.

up period. Two patients are still on food elimination diet.

Four of the patients were hospitalized and median length of hospital stay was 9 days (IQR 5 to 21 days). Parenteral acyclovir and systemic antibiotherapy were administered to four of the patients. In one case, antimicrobial therapy was not administered because the lesions were crusted and there were no active vesicles at the time of diagnosis. The treatments applied before and after the diagnosis of $\mathrm{EH}$ are summarized in Table III.

An informed consent to publish the case report including the photos was obtained from parents of the patients.

\section{Discussion}

Atopic dermatitis is a chronic inflammatory skin disease characterized by intense pruritus with frequent relapsing courses with a higher incidence of certain cutaneous infections. ${ }^{5}$

Eczema herpeticum is one of the cutaneous infections in association with AD. The incidence of $\mathrm{EH}$ has not been well defined but it is known to be with a mortality of 1-9\%. Most commonly
HSV type 1 and also HSV type 2, Coxcakie Virus A16, Vaccinia Virus, Varicella Zoster Virus are the contributing infectious etiologies that affect patients with $\mathrm{EH}^{4,6}$ The pathogenesis of $\mathrm{EH}$ is not completely understood. In a study it was reported that faster replication of HSV was observed in damaged skin than in normal skin. ${ }^{7}$ High levels of serum IgE, serum eosinophil counts, thymus and activation regulated chemokine have also been associated with a higher risk of developing $\mathrm{EH}$ in patients with AD. ${ }^{8}$

Eczema herpeticum is a clinical diagnosis and characterized by grouping vesiculopustules followed by crusted, hemorrhagic, punched-out ulcers on the skin affected by a pre-existing dermatosis. ${ }^{4}$ Secondary bacterial infection, mostly due to $S$. aureus, often occurs because of the inflammatory and extensive nature of the process. ${ }^{9}$ In all of our patients, characteristic vesiculo-pustules were observed on the pre-existing dermatitis. Secondary impetiginization was common on the affected area which made the clinic difficult to diagnose accurately. In the patients with pre-existing $\mathrm{AD}$ with $\mathrm{EH}$, underlying viral etiology may be underrecognized and misdiagnosed as $\mathrm{AD}$ 


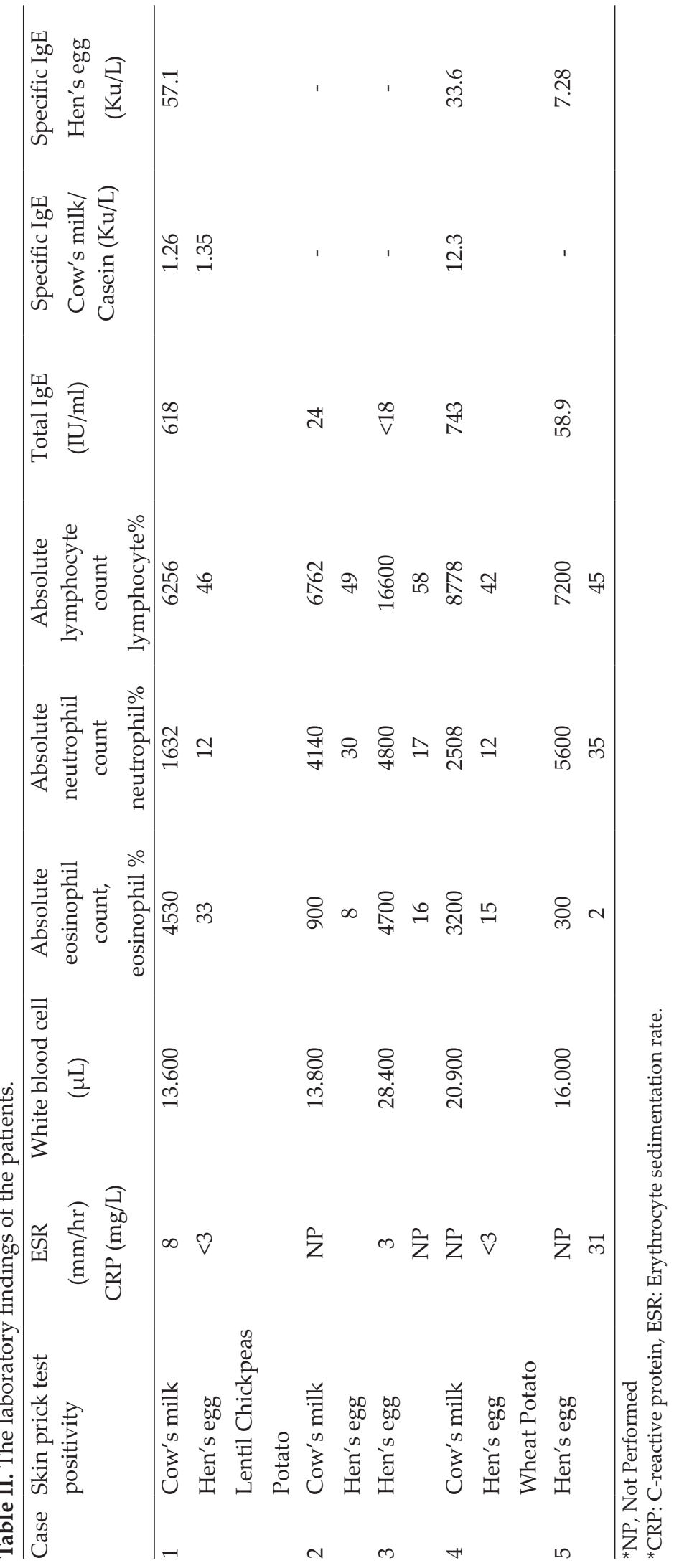


Table III. The treatments applied before and after the diagnosis of Eczema herpeticum.

\begin{tabular}{|c|c|c|c|c|c|c|}
\hline \multirow[t]{2}{*}{ Case } & \multirow{2}{*}{$\begin{array}{l}\text { Duration of TCS* } \\
\text { usage before EH } \\
\text { (week) })^{* *}\end{array}$} & \multicolumn{5}{|c|}{ Treatment of EH } \\
\hline & & $\begin{array}{l}\text { Parenteral } \\
\text { acyclovir }\end{array}$ & $\begin{array}{l}\text { Parenteral } \\
\text { antibiotic }\end{array}$ & TCS+ & $\begin{array}{c}\text { Topical } \\
\text { antibiotic }\end{array}$ & Anti-histamine \\
\hline 1 & 8 & + & + & + & + & + \\
\hline 2 & 20 & - & - & + & + & - \\
\hline 3 & 6 & + & + & + & - & - \\
\hline 4 & 4 & + & + & + & - & + \\
\hline 5 & 1 & + & + & + & + & - \\
\hline
\end{tabular}

*TCS: Topical corticosteroid.

**TCS treatment was applied intermittently, not all days of the week

+Topical corticosteroid was not applied in the active disease period

ED: Eczema herpeticum

exacerbation or as impetiginization. The upper body is the most common site of infection, with a predilection for the head and neck. ${ }^{10}$ The most frequently affected area in all of our patients was the head, followed by extremities and trunk involvement.

Eczema herpeticum is associated with a flu-like syndrome, fever, malaise, lymphadenopathy and may be complicated by keratoconjunctivitis, meningitis and encephalitis. ${ }^{11}$ We observed fever and restlessness in one case but did not observe central nervous system involvement findings in any of the patients.

Eczema herpeticum occurs most commonly in association with AD. However, it can also be seen in the course of other skin diseases that disrupt epidermal integrity such as psoriasis, pemphigus vulgaris, pemphigus foliaceus, pityriasis rubra pilaris, contact dermatitis (irritant and allergic), seborrheic dermatitis, cutaneous T-cell lymphoma. ${ }^{12}$

Our cases had early onset moderate to severe AD. Three cases were accompanied by seborrheic dermatitis on the head. Beck et al. ${ }^{8}$ reported that patients who had $\mathrm{AD}$ with a history of $\mathrm{EH}(\mathrm{ADEH})$ had more severe AD, an earlier onset of skin disease and a higher prevalence of associated allergic diseases such as food allergy or asthma. In the study clinical features of $\mathrm{ADEH}+$ versus $\mathrm{ADEH}-$ subjects were compared. ADEH+ patients were more commonly sensitized to many common allergens and higher serum total $\operatorname{IgE}$ and absolute eosinophil count was detected. Similarly, in our cases high levels of eosinophil count and total IgE was observed and all patients were sensitized to food allergens. Eosinophilia is a predictable finding in cases of AD with food allergy. However, the presence of moderate to severe eosinophilia in our patients is noteworthy. Three of our patients were found to have hypereosinophilia $\left(>1500 / \mathrm{mm}^{3}\right)$. One of the patients with hypereosinophilia improved clinically within six months and had no more eosinophilia on peripheral blood smear, while the other two patients continued with recurrent severe AD exacerbations and high eosinophil counts. Neither AD nor food allergy would be enough to explain the resistant and longstanding eosinophilia in these patients. We anticipate that an undefined immunological and/or genetic mechanism may lead to this predisposition to high allergy load and EH.

The diagnosis of our patients was made clinically by a pediatric allergist and a dermatologist. None of the patients had positive HSV serology which was taken from the peripheral blood sample at the active disease period. After active period HSV serology was not re-evaluated and this might have led to false negativity in serological evaluation. But in one of the patients HSV PCR positivity was detected from the sample taken from the cerebrospinal fluid. Supporting the clinical diagnosis; Tzank test has the highest sensitivity when compared to $\mathrm{PCR}$, electron 
microscopy, immunofluorescence, viral culture and serological tests. ${ }^{13}$ For our patients Tzanck test was not performed. The low sensitivity of supporting laboratory tests in the diagnosis of $\mathrm{EH}$ further heightens the importance of clinical diagnosis. Clinical suspicion is essential and initiation of antiviral treatment should not be postponed.

Morbidity and mortality of EH can be minimized by starting antiviral therapy at the earliest time in diagnosis. The main treatment is acyclovir. Systemic antivirals and hospitalization are recommended for severe disease and immunocompromised patients. Secondary bacterial infection (mostly due to Staphylococcus aureus, streptococcus pyogenes and pseudomonas) which can hide the underlying viral pathogenesis and sepsis are the most important complications, and therefore systemic antibiotherapy should be added when necessary. ${ }^{9}$ Parenteral acyclovir and systemic antibacterial therapy were given in patients except one whose skin lesions were all crusted and recovering at the time of the diagnosis. During the six months follow up of our patients, recurrence of $\mathrm{EH}$ was not observed.

Despite the high prevalence of AD in childhood, $\mathrm{EH}$ is a rare but severe and potentially fatal condition. ${ }^{14}$ The eruption of $\mathrm{EH}$ in the patients with $\mathrm{AD}$ is usually misdiagnosed as an exacerbation of $\mathrm{AD}$ and causes delay in diagnosis with the use of unnecessary longterm potent local steroids. For all that delay in diagnosis leads to increased complications such as herpetic keratitis, viremia, sepsis and death. ${ }^{9}$

In patients with early onset, moderate to severe AD, when newly formed, local steroidresistant vesiculopapular puched out lesions are recognised on the present dermatitis lesion, $\mathrm{EH}$ should be considered in the differential diagnosis. Infants with food allergy who have moderate to severe eosinophilia constitute a prominent risk group. Careful history taken with the awareness of the risk factors and characteristic cutaneous findings pointing $\mathrm{EH}$ will be helpful for the accurate diagnosis. The laboratory evaluation is not diagnostic but helpful for supporting the clinic. Early diagnosis and antiviral treatment on time can prevent major complications and death.

\section{REFERENCES}

1. Lee SI, Kim J, Han Y, Ahn K. A proposal: Atopic Dermatitis Organizer (ADO) guideline for children. Asia Pac Allergy 2011; 1: 53-63.

2. Schneider L, Tilles S, Lio P, et al. Atopic dermatitis: a practice parameter update 2012. J Allergy Clin Immunol 2013; 131: 295-299.e1-27.

3. Olson J, Robles DT, Kirby P, Colven R. Kaposi varicelliform eruption (eczema herpeticum). Dermatol Online J 2008; 14: 18.

4. Ferrari B, Taliercio V, Luna P, Abad ME, Larralde M. Kaposi's varicelliform eruption: a case series. Indian Dermatol Online J 2015; 6: 399-402.

5. Narla S, Silverberg JI. Association between atopic dermatitis and serious cutaneous, multiorgan and systemic infections in US adults. Ann Allergy Asthma Immunol 2018; 120: 66-72.e11.

6. Hsu DY, Shinkai K, Silverberg JI. Epidemiology of eczema herpeticum in hospitalized U.S. children: analysis of a nationwide cohort. J Invest Dermatol 2018; 138: 265-272.

7. Santmyire-Rosenberger BR, Nigra TP. Psoriasis herpeticum: three cases of Kaposi's varicelliform eruption in psoriasis. J Am Acad Dermatol 2005; 53: 52-56.

8. Beck LA, Boguniewicz M, Hata T, et al. Phenotype of atopic dermatitis subjects with a history of eczema herpeticum. J Allergy Clin Immunol 2009; 124: 260269. 269.e1-e7.

9. Liaw FY, Huang CF, Hsueh JT, Chiang CP. Eczema herpeticum: a medical emergency. Can Fam Physician 2012; 58: 1358-1361.

10. Vora RV, Pilani AP, Jivani NB, Kota RK. Kaposi varicelliform eruption. Indian Dermatol Online J 2015; 6: 364-366.

11. Leung DY. Why is eczema herpeticum unexpectedly rare? Antiviral Res 2013; 98: 153-157.

12. Chia KY, Ho MS, Tey HL. A less known dermatological emergency. Ann Acad Med Singapore 2012; 41: 366-367.

13. Sohail M, Khan FA, Shami HB, Bashir MM. Management of eczema herpeticum in a Burn Unit. J Pak Med Assoc 2016; 66: 1357-1361.

14. Kim K, Kang J, Won Kim S, Sung M. Relationship between the presence of eczema herpeticum and the significance of clinical and laboratory tests in Korean childrenwith atopic dermatitis. Iran J Pediatr 2016; 26: e4683. 